\title{
PSYCHOSOCIAL AND ORGANISATIONAL WORK ENVIRONMENT OF NURSE MANAGERS AND SELF-REPORTED DEPRESSIVE SYMPTOMS: CROSS-SECTIONAL ANALYSIS FROM A COHORT OF NURSE MANAGERS
}

\author{
NATHALIE NOURRY ${ }^{1,2}$, AMANDINE LUC ${ }^{3}$, FRANÇOIS LEFEBVRE ${ }^{4}$, HÉLÈNE SULTAN-TAÏEB ${ }^{5}$, and SOPHIE BÉJEAN ${ }^{2}$ \\ ${ }^{1}$ University of Strasbourg, Strasbourg, France \\ Faculty of Medicine, Department of Occupational Medicine and of Occupational Pathology \\ ${ }^{2}$ University of Bourgogne, CNRS, Dijon, France \\ Laboratory of Management and Economics (LEG), FRE 3496 \\ ${ }^{3}$ University of Lorraine, Nancy, France \\ INGRES, EA7298 \\ ${ }^{4}$ Teaching Hospitals of Strasbourg, Strasbourg, France \\ Department of Biostatistics \\ ${ }^{5}$ University of Québec in Montréal (UQAM), Interdisciplinary Research Centre on Biologie, \\ Health, Society and the Environment (CINBIOSE), Montréal, Canada \\ Department of Organisation and Human Resources, School of Sciences and Management
}

\begin{abstract}
Objectives: The association between depressive symptoms and psycho-organisational work environment has been established in the literature. Some studies have evaluated depressive symptoms in healthcare workers, but little research has been carried out among nurse managers. The aim of the study is to evaluate the depressive symptoms prevalence among nurse managers' population and work environment factors. Material and Methods: A descriptive correlational research design was used. Data were collected from 296 nurse managers in five hospitals in the eastern area of France between 2007 and 2008. Health outcomes were evaluated by measuring depressive symptoms (CES-D scale), the exposure data by assessing psycho-organisational work environment with effort-reward imbalance-model of Siegrist. Multiple logistic regressions were used to describe the strength of the association between depressive symptoms and effort-reward imbalance adjusted for personal and occupational characteristics of the nurse managers. Results: Among the nurse managers, a third had depressive symptoms, and 18\% presented an effort-reward imbalance (ratio: $\geq 1$ ). A significant association was found between depressive symptoms and effort-reward imbalance $\left(\mathrm{OR}=10.81,95 \% \mathrm{CI}: 5.1-23, \mathrm{p}<10^{-3}\right)$, and with esteem as a reward (OR = 3.21, 95\% CI: 1.6-6.3, $\left.\mathrm{p}<10^{-2}\right)$. Conclusion: In view of the hierarchical situation of nurse managers and their primary roles in hospitals, it is necessary to take prevention measures to improve their work environment and health.
\end{abstract}

Key words:

Depression, Mental health, Psychosocial constraints, Effort-reward imbalance, Nurse managers, Health care workers

Received: October 4, 2013. Accepted: February 5, 2014.

Corresponding author: N. Nourry, University of Strasbourg, Faculty of Medicine, Department of Occupational Medicine and Occupational Pathology,

1 place de l'hôpital 67091 Strasbourg Cedex, France (e-mail: nathalie.nourry@unistra.fr). 


\section{INTRODUCTION}

Depression is a pathology with a significant prevalence in Europe and in France [1-5]. Annual medical costs of depression can be estimated at 1.9 billion Euros in 2011 in France [6,7]. In terms of costs borne by employers, absenteeism is associated with a high amount of days lost $[8,9]$. Furthermore, it is known that the risk of recurrence of depressive symptoms is major when patients had to take sick days for depression [10]. But, according to several authors, the cost of presenteeism for workers suffering from depression is higher than the cost of absenteeism [11,12]. Thus, in his study in 2003, Stewart showed that $81 \%$ of the lost productive time among depressive workers corresponds to reduced performance while at work. In a recent study on the economic burden of depression in South Korea, indirect costs related to presenteeism represented $44.7 \%$ of the total cost of depression, and $28.4 \%$ for absenteeism in 2005 [13].

Within the health care workers profession, several studies were conducted among registered nurses [14-16], nurse aids [17,18], physicians [19-23], on their burnout syndrome, their depressive symptoms or their health [24].

Nurse managers in hospital are more scarcely studied compared with other health care workers. Some studies have produced insights about their ill-being, degree of satisfaction, leadership and recruitment [25-27]. But very few studies analysed their health in relation to their organisational work environment. Concerning their health, a study carried out by Lindholm et al. in Sweden investigated self-rated health, sick leave of nurse managers according to their professional networks, psychosocial work conditions, job support, social network and support. An association was found between high job demands and low self-rated health [28]. A study carried out in Japan showed that a lack of assertiveness and satisfaction was associated with burnout among Japanese nurse managers [29]. Another study examined the influence of effort-reward imbalance on burnout level among nurse managers and showed that personal (lack of coreself evaluation) and situational (effort-reward imbalance ratio) factors were significant predictors of the score of burnout [30].

In France, only 2 studies about the health of nurse managers were published. Fanello et al. [31] analysed the mental health of 97 nurse managers using the standardised mental health questionnaire - GHQ-12 for health - questions to define their social and occupational characteristics and workplace experience. They demonstrated that $1 / 3$ of participants were considered to be in psychological distress, that the lack of reward was associated with psychological distress of nurse managers. The second study was the European Press Next study carried out in France among a population of health care workers including nurse managers [32]. A total of $28 \%$ of nurse managers reported suffering from mental diseases.

Associations between the organisational work environment, stress and depressive symptoms have been established in the literature in the general population [33-35]. To describe the psycho-organisational work environment, different scales were established and validated. The 2 models from Karasek [36,37] and Siegrist [38,39] were translated into French, and their psychometric properties were studied in the French population [40-44].

Several studies showed links between the effort-reward imbalance and depressive symptoms or self-health assessments. The risk of depression ranged from 1.5 to 4.6 with the effort-reward imbalance model $[33,38,45]$ and it was lower with the Karasek model, ranging from 1.58 to 3.3 for men and 1.2 to 2.8 for women $[34,46,47]$. The effortreward imbalance model allowed evaluating 3 principal dimensions: effort, reward and over commitment. The model was based on the need of reward to balance the effort at work in relation to the social reciprocity theory. High effort and low reward also lead to emerging stress. The third dimension, over commitment, completes the models, thus, a population with higher over commitment 
is prone to respond with more stress to effort-reward imbalance [38].

The objectives of the paper are to describe the prevalence of depressive symptoms among a large nurse manager population, and to produce estimates of the association between depressive symptoms measured with the CES-D instrument and effort-reward imbalance according to Siegrist's model.

A lot is at stake since nurse managers, as line managers, are the link between senior management and the health care staff (except physicians) in French hospitals. They play a very important role as team managers. The mental health, the well-being of staff of health care services are better when there is good management carried out by nurse managers. They also play an important role to prevent conflicts in nursing [48-50]. That's why it is important to be aware of the health status of the nurse manager population and to identify the diseases that can be associated with stress at work.

\section{MATERIAL AND METHODS}

This cross-sectional study was carried out between 2007-2008 in 5 hospitals from the eastern area of France. Among these hospitals, there were 4 teaching hospitals, and 1 general hospital. The principal objective of this study was to describe the health, the work environment and the consumption of health services of the nurse manager population. Their mental health and musculoskeletal disorders were the focus of the evaluation. Data was collected through a self-administered questionnaire.

Before starting the study, in each hospital, information was given in nurse managers meetings and in committees dealing with work conditions. Each nurse manager was individually informed of the purpose and the aim of the study. The nurse managers were to voluntary answer the anonymous questionnaire.

\section{Study population}

Each participating hospital sent the questionnaire to all of their nurse managers, which represents a total population of approximately 500 nurse managers. The inclusion criteria were to manage nurses in hospitalisation units, emergency units or in operating theatre. Three hundred thirty nine nurse managers filled up the questionnaire with a response rate of $67 \%$. Among the 339 respondents, those managing health care workers in radiological units or medical laboratories were excluded $(\mathrm{N}=33)$.

Managers not active in management positions were also excluded $(\mathrm{N}=3)$. Moreover, 7 questionnaires were not analysed because of missing data. As a result, 296 questionnaires were analysed in this study.

\section{Measurement}

Depressive symptoms (dependant variable)

The Center for Epidemiological Study Depression survey (CES-D) questionnaire was used in the 20 -item version [51]. The items evaluated the presence of depressive symptoms related to major or clinical depression in the previous week. That is a screening measure, not a diagnostic tool. The items include depressed mood, feelings of guilt, worthlessness and helplessness, psychomotor retardation, loss of appetite and sleep difficulties. Depression was defined by the obtained CES-D score, equal or higher than 17.

To answer, the nurse managers were asked to choose a response from a four-point Likert scale: from "less than one day" (0) to "5 to 7 days" (3). The sum of the score of each response was calculated after the answers to the positive questions were reversed. The sum ranges from 0 to 60 . The internal consistency of the questionnaire was appropriate ( $\alpha$ Cronbach for our whole sample $=0.921)[52]$.

Imputation procedure was used for missing data with less than 5 missing answers following usual practice. 
A cut-point of $\geq 17$ was used to make a dichotomous variable for men and women.

\section{Effort-reward imbalance model (independent variable)}

The scale of Siegrist effort-reward imbalance model was used [38]. According to this model, there is an imbalance between the effort and the reward, when the subject produces more effort than it receives rewards. This imbalance causes stress.

The French validated version of the Siegrist model with 23 items was used. Six items were related to effort, eleven to reward and six to over commitment. The reward component includes three subscales: money, esteem and career opportunities. The higher the reward score, the higher the lack of reward. The internal consistency of the effort dimension was verified ( $\alpha$ Cronbach: 0.804); along with the reward dimension ( $\alpha$ Cronbach: 0.849). They were correct and consistent with psychometric properties [43]. When only 1 piece of data was missing for effort and 2 for reward, they were replaced by their respective median in line with usual practice. To compute the score, we used the method described by Niedhammer and Siegrist [39,42]. A dichotomous variable was defined. People with effort-reward imbalance ratio higher than one were considered as exposed to work stress. Tertiles of the distribution of the effort-reward imbalance were analysed to explore a dose-response relationship between the effort-reward imbalance and the depressive symptoms. For each dimension and subscales, a dichotomous variable was defined according to the median score of the whole population.

Concerning the over commitment scale, the second tertile of the whole population was used to define a dichotomous variable as was recommended by Niedhammer and Siegrist $[39,42]$.

Potential Occupational confounding variables

Participants specified the specialty area of their units (health care service, emergency and intensive care, operating theatre), their employment status (full time/ part time) and their work schedules (days only/other). Data about the organisational work environment over the previous 12 months were also collected concerning: events that might have changed or disturbed the organisation of the work environment, research activity, inexperienced residents, practical restructuring or architectural restructuring, disputes that could disturb organisation, or organisational issues that could be at the root of conflicts. There were also 4 questions about the support given by the administration, the physicians, the nurse chief managers and the technical support.

Those questions had been created for and tested in the ORSOSA study [16,53]. Disputes that disturbed organisation and organisational issues that could be at the root of conflicts were encoded as binary variables. Answers were divided into 2 categories: none versus at least one. Support variables were divided into 2 categories: agree or not agree.

\section{Other potential confounding variables}

There were 3 groups of potential confounding variables: sociodemographic factors, behavioural factors, trait anxiety.

Gender and age of nurse managers were collected. Three age classes were created ( $<40,40-49$, and $\geq 50$ years).

The collection of height and weight allowed to calculate the body mass index (BMI), four classes were created following the World Health Organization recommendations $(<18.5,18.5-24,25-29, \geq 30)$. The smoker status of nurse managers was asked (no smoker, current smoker, and former smoker). Alcohol consumption was collected by the number of French standard glasses per day (10 $\mathrm{g}$ of pure alcohol/glass), 2 categories were defined below and over 1 glass per day. The last behavioural factor was sports activity (number of hours of sports activity per week). Two classes were considered: $1 \mathrm{~h}$ or more per week and no sports activity. 
Trait anxiety was evaluated by the Spielberg scale, the statetrait anxiety inventory (STAI). The Likert 20 items that determine trait anxiety of the Y version were used [54].

\section{STATISTICAL ANALYSIS}

Differences in depressive symptoms status were analysed with the chi-squared test or Fisher's exact test when the expected values were below 5. Multivariate logistic regression analysis was used to calculate odd ratios (ORs) and their $95 \%$ confidence interval for depressive symptoms.

Independent variables to include in the models of multivariate logistic regression were chosen according to $\mathrm{p}$ value calculated for univariate analyses. The criteria for including a variable was a $p$ value lower than 0.20.

A correlation table was made (not shown) and if two explanatory variables were very highly correlated, the variable with the highest association with depressive symptoms was included in the models.

The association between depressive symptoms and the effort-reward imbalance ratio was analysed separately in 4 stepwise adjusted models:

- Model 1 was adjusted for personal characteristics: sociodemographic variable (gender), behavioural variables (sports activity and smoking status).

- Model 2 was adjusted for occupational characteristics: experience, employment status, specialty area, events that happened over the previous 12 months.

- Model 3 was adjusted for personal and occupational characteristics.

- Model 4 is a logistic backward stepwise regression adjusted for personal and occupational characteristics.

Three other models were made without effort-reward imbalance ratio, but with effort and reward scores (dichotomous variables according to median) in model 5; and effort, esteem, career opportunity and money (dichotomous variables according to median) in models 6 and 7.
The statistical significance level for all of the analyses was set at 0.05 . All of the analyses were carried out using SPSS version 21.

\section{RESULTS}

This sample comprised 296 French nurse managers (mean age: $46.2, \mathrm{SD}=7.4)$, there were $32(11 \%)$ males and 264 (89\%) females. Thirty-one percent had depressive symptoms during the previous 7 days. The mean depression score was 13.3 (SD = 9.1).

In terms of personal factors, about 36 percent of the nurse managers were overweight $(\mathrm{BMI} \geq 25)$ and $58 \%$ had never smoked.

Almost all of the nurse managers worked full time $(96.9 \%)$, days only $(81.6 \%)$ in a health care unit $(72 \%)$, in emergency and intensive care unit $(17 \%)$ or operating theatre $(11 \%)$. The median of their experience was 7 years. The nurse managers reported inadequate physician support (42.5\%), inadequate administration support (66.2\%), inadequate technical support $(71.1 \%)$ and inadequate nurse chief manager support (only 15.8\%). Concerning the events that happened over the previous 12 months, the nurse managers reported practical restructuring $(76.3 \%)$, architectural restructuring $(24.1 \%)$, at least one dispute that could disturb work organisation (52.9\%), at least one dispute rising from organisational issues that could be at the root of conflicts (69.9\%). Table 1 shows these results.

Concerning the psycho-organisational factors of Siegrist's model, about $17.6 \%$ were considered to perceive a high level of effort-reward imbalance (ratio: $\geq 1$ ). The median effort-reward ratio was at 0.68 , with the median of effort dimension at 17 and reward dimension at 21. For over commitment, $37.8 \%$ of the nurse managers were over the upper tertile.

Table 2 presents the work psychosocial environment results of Siegrist's model. 
Table 1. Medical, socio demographic, behavioural, anthropometric and occupational characteristics of the population according to depressive symptoms

\begin{tabular}{|c|c|c|c|c|c|}
\hline \multirow{2}{*}{ Variables } & \multicolumn{2}{|c|}{ Whole population } & \multicolumn{2}{|c|}{$\begin{array}{c}\text { Depressive symptoms } \\
{[\mathrm{n}(\%)]} \\
\end{array}$} & \multirow{2}{*}{$\mathrm{p}$} \\
\hline & $\begin{array}{c}\text { observations } \\
\text { (n) }\end{array}$ & $\mathrm{n}(\%)$ & yes & no & \\
\hline Whole population & 296 & $296(100)$ & $91(31.0)$ & $205(69.0)$ & - \\
\hline Anxiety trait - STAI YB > 45 & 296 & $73(25)$ & $55(60.4)$ & $18(8.8)$ & $<10^{-3}$ \\
\hline Age (years) & 296 & & & & 0.48 \\
\hline$<40$ & & $65(22)$ & $16(17.6)$ & $49(23.6)$ & \\
\hline $40-49$ & & $120(40)$ & $39(42.9)$ & $81(39.5)$ & \\
\hline$\geq 50$ & & $111(38)$ & $36(39.6)$ & $75(36.6)$ & \\
\hline Gender & 296 & & & & $<10^{-2}$ \\
\hline female & & $264(89)$ & $88(96.7)$ & $176(85.9)$ & \\
\hline male & & $32(11)$ & $3(14.1)$ & $29(3.3)$ & \\
\hline Body mass index & 295 & & & & 0.22 \\
\hline$<18.5$ & & $4(1)$ & & & \\
\hline $18.5-25$ & & $186(63)$ & $62(68.1)$ & $124(60.8)$ & \\
\hline $25-30$ & & $78(26)$ & $18(19.8)$ & $60(29.4)$ & \\
\hline$\geq 30$ & & $31(11)$ & $11(12.1)$ & $20(9.8)$ & \\
\hline Smoking status & 296 & & & & 0.19 \\
\hline no smoking & & $171(58)$ & $53(58.2)$ & $118(57.6)$ & \\
\hline former smoking & & $68(23)$ & $16(17.6)$ & $52(25.4)$ & \\
\hline current smoking & & $57(19)$ & $22(24.2)$ & $35(17.1)$ & \\
\hline Sports activity $\geq 1 \mathrm{~h} /$ week & 296 & $208(30)$ & $53(58.2)$ & $155(75.6)$ & $<10^{-2}$ \\
\hline Alcohol consumption $\geq 1$ glass/day & 295 & $43(15)$ & $12(13.2)$ & $31(15.2)$ & 0.65 \\
\hline Work time & 292 & & & & 0.13 \\
\hline full time & & $283(97)$ & $83(94.3)$ & $204(98.0)$ & \\
\hline part time & & $9(3)$ & $5(5.7)$ & $4(2.0)$ & \\
\hline Schedule & 293 & & & & 0.84 \\
\hline days only & & $239(82)$ & $74(82.2)$ & $165(81.3)$ & \\
\hline other & & $54(18)$ & $16(17.8)$ & $38(18.7)$ & \\
\hline Seniority (years) & 296 & & & & 0.54 \\
\hline$\leq 3$ & & $101(34)$ & $30(33.0)$ & $71(34.6)$ & \\
\hline $4-10$ & & $78(26)$ & $21(23.1)$ & $57(27.8)$ & \\
\hline$\geq 11$ & & $117(40)$ & $40(44.0)$ & $77(37.6)$ & \\
\hline Specialty area & 296 & & & & 0.02 \\
\hline health care service & & $212(72)$ & $55(60.4)$ & $157(76.6)$ & \\
\hline emergency and intensive care & & $51(17)$ & $21(23.1)$ & $30(14.6)$ & \\
\hline operating theatre & & $33(11)$ & $15(16.5)$ & $18(8.8)$ & \\
\hline \multicolumn{6}{|l|}{ Inadequate support } \\
\hline by physicians & 294 & $125(42)$ & $56(61.5)$ & $69(34.0)$ & $<10^{-3}$ \\
\hline
\end{tabular}


Table 1. Medical, socio demographic, behavioural, anthropometric and occupational characteristics of the population according to depressive symptoms - cont.

\begin{tabular}{|c|c|c|c|c|c|}
\hline \multirow{2}{*}{ Variables } & \multicolumn{2}{|c|}{ Whole population } & \multicolumn{2}{|c|}{$\begin{array}{c}\text { Depressive symptoms } \\
{[\mathrm{n}(\%)]} \\
\end{array}$} & \multirow{2}{*}{$\mathrm{p}$} \\
\hline & $\begin{array}{l}\text { observations } \\
\text { (n) }\end{array}$ & $\mathrm{n}(\%)$ & yes & no & \\
\hline by administration & 293 & $194(66)$ & $66(72.5)$ & $128(63.4)$ & 0.12 \\
\hline by nurse manager chief & 292 & $46(16)$ & $25(27.8)$ & $21(10.4)$ & $<10^{-3}$ \\
\hline technical support & 291 & $207(71)$ & $67(77.0)$ & $140(68.6)$ & 0.15 \\
\hline \multicolumn{6}{|l|}{ Over the 12 previous months } \\
\hline research activity & 293 & $180(61.4)$ & $56(61.5)$ & $124(61.4)$ & 0.9 \\
\hline inexperienced residents & 292 & $136(46.6)$ & $26(28.6)$ & $110(54.7)$ & $<10^{-3}$ \\
\hline practical restructuring & 295 & $225(76)$ & $77(84.6)$ & $148(72.5)$ & 0.02 \\
\hline architectural restructuring & 295 & $71(24)$ & $19(20.9)$ & $52(25.5)$ & 0.39 \\
\hline $\begin{array}{l}\text { to have at least once dispute that disturbs } \\
\text { organisation }\end{array}$ & 293 & $155(53)$ & $60(38.7)$ & $95(61.3)$ & $<10^{-2}$ \\
\hline $\begin{array}{l}\text { to have at least once reorganisation that } \\
\text { creates dispute }\end{array}$ & 296 & $207(70)$ & $78(37.7)$ & $129(62.3)$ & $<10^{-3}$ \\
\hline one training session at least & 296 & $207(69.9)$ & $66(72.5)$ & $141(68.8)$ & 0.52 \\
\hline
\end{tabular}

STAI YB - state-trait anxiety inventory form Y.

Table 2. Psycho-organisational factors in nurse managers according to depressive symptoms

\begin{tabular}{|c|c|c|c|c|c|}
\hline \multirow{2}{*}{ Psycho-organisational factors } & \multicolumn{2}{|c|}{ Whole population } & \multicolumn{2}{|c|}{$\begin{array}{c}\text { Depressive symptoms } \\
{[\mathrm{n}(\%)]}\end{array}$} & \multirow{2}{*}{$\mathrm{p}$} \\
\hline & $\begin{array}{l}\text { observations } \\
\text { (n) }\end{array}$ & $\mathrm{n}(\%)$ & yes & no & \\
\hline \multicolumn{6}{|l|}{ Siegrist } \\
\hline $\begin{array}{l}\text { mean effort-reward imbalance } \\
\text { (continuous) }\end{array}$ & 296 & $0.78 \pm 0.4^{*}$ & $1.03 \pm 0.4^{*}$ & $0.67 \pm 0.3^{*}$ & $<10^{-3}$ \\
\hline effort reward imbalance ratio (> 1) & 296 & $52(18)$ & $39(42.9)$ & $13(6.3)$ & $<10^{-3}$ \\
\hline \multicolumn{6}{|l|}{ effort reward ratio divided in tertiles } \\
\hline low effort reward ratio & 106 & $106(35.8)$ & $9(9.9)$ & $97(47.3)$ & \\
\hline medium effort reward ratio & 91 & $91(30.7)$ & $26(28.6)$ & $65(31.7)$ & \\
\hline high effort reward ratio & 99 & $99(33.4)$ & $56(61.5)$ & $43(21.0)$ & \\
\hline Effort (> median) & 296 & $154(52.0)$ & $73(80.2)$ & $81(39.5)$ & $<10^{-3}$ \\
\hline Rewards (> median) & 296 & $153(51.7)$ & $74(81.3)$ & $79(38.5)$ & $<10^{-3}$ \\
\hline Esteem (> median) & 296 & $164(55.4)$ & $72(79.1)$ & $92(44.9)$ & $<10^{-3}$ \\
\hline Career opportunity (> median) & 296 & $174(58.8)$ & $70(76.9)$ & $104(50.7)$ & $<10^{-3}$ \\
\hline Money (> median) & 296 & $203(68.6)$ & $69(75.8)$ & $134(65.4)$ & 0.07 \\
\hline Over commitment ( $\geq$ upper tertile) & 296 & $112(38.0)$ & $56(61.5)$ & $56(27.3)$ & $<10^{-3}$ \\
\hline
\end{tabular}

* Mean \pm standard deviation. 
Table 3. Each dimension and subscale of effort-reward model according to depressive symptoms

\begin{tabular}{|c|c|c|c|c|c|c|c|c|c|c|c|c|c|}
\hline \multirow{3}{*}{$\begin{array}{c}\text { Scale and subscale } \\
\text { of effort-reward } \\
\text { model }\end{array}$} & \multirow{2}{*}{\multicolumn{5}{|c|}{ Whole population }} & \multicolumn{8}{|c|}{ Depressive symptoms } \\
\hline & & & & & & \multicolumn{4}{|c|}{ yes } & \multicolumn{4}{|c|}{ no } \\
\hline & $\mathrm{n}$ & $\mathrm{Me}$ & $\min$. & $\max$ & $\mathrm{p}$ & $\mathrm{n}$ & $\mathrm{Me}$ & $\min$. & $\max$ & $\mathrm{n}$ & $\mathrm{Me}$ & $\min$. & $\max$ \\
\hline Effort-reward ratio & 296 & 0.68 & 0.27 & 2.75 & $<10^{-3}$ & 205 & 0.62 & 0.27 & 2.53 & 91 & 0.94 & 0.48 & 2.75 \\
\hline Over commitment & 296 & 17.00 & 10.00 & 30.00 & $<10^{-3}$ & 205 & 17.00 & 10.00 & 30.00 & 91 & 19.00 & 13.00 & 25.00 \\
\hline Effort & 296 & 17.00 & 8.00 & 29.00 & $<10^{-3}$ & 205 & 16.00 & 8.00 & 29.00 & 91 & 19.00 & 11.00 & 28.00 \\
\hline Reward & 296 & 21.00 & 11.00 & 52.00 & $<10^{-3}$ & 205 & 19.00 & 11.00 & 46.00 & 91 & 27.00 & 13.00 & 52.00 \\
\hline Esteem & 296 & 8.00 & 5.00 & 24.00 & $<10^{-3}$ & 205 & 7.00 & 5.00 & 23.00 & 91 & 13.00 & 5.00 & 24.00 \\
\hline Career opportunity & 296 & 7.00 & 1.00 & 24.00 & $<10^{-3}$ & 205 & 7.00 & 1.00 & 21.00 & 91 & 11.00 & 1.00 & 24.00 \\
\hline Money & 296 & 3.00 & 1.00 & 5.00 & 0.08 & 205 & 3.00 & 1.00 & 5.00 & 91 & 3.00 & 1.00 & 5.00 \\
\hline
\end{tabular}

Me - median; min. - minimal value; max - maximal value.

In Table 1 and 2, univariate analyses between depressive symptoms and personal and occupational characteristics are also presented. Different subscales of effort-reward imbalance are presented in Table 3. Only the money subscale was not significantly associated with depressive symptoms.

As shown in Table 4, effort-reward imbalance and the following covariables, gender, sports activity, specialty area, were all significantly associated with depressive symptoms after adjustment for all of the other factors and with a logistic backward stepwise regression. The effort-reward imbalance has a very high significant association with the depressive symptoms (OR $=10.81,95 \% \mathrm{CI}: 5.1-23)$. There were more significantly depressive symptoms among females (OR $=6.25,95 \%$ CI: $1.6-23.9)$, among the nurse managers of emergency and intensive care units $(\mathrm{OR}=2.41,95 \% \mathrm{CI}: 1.1-5.2)$ and operating theatres (OR $=2.56,95 \%$ CI: $1.7-6.2)$. Sports activity was associated with protective effect $(\mathrm{OR}=0.37,95 \% \mathrm{CI}$ : $0.20-0.77)$.

The use of categorical variables of effort-reward ratio showed a dose-response relationship, nurse managers with higher effort-reward ratio $(\mathrm{OR}=14.04,95 \% \mathrm{CI}$ : 6.4-40.4) reported depressive symptoms significantly more often after adjustment for all of the other factors than the nurse managers with medium effort-reward ratio (OR $=4.50,95 \%$ CI: 1.8-11.4).

A new model, based (model 5) on model 3, was analysed; it included effort and reward scores in the place of the effort-reward imbalance ratio. There was a significant association between the depressive symptoms and effort $(\mathrm{OR}=4.22,95 \% \mathrm{CI}: 2.1-8.6)$, and reward $(\mathrm{OR}=3.67,95 \% \mathrm{CI}: 1.0-7.6)$. When the reward dimension was replaced with the subscales of reward: esteem, career opportunity and money (models 6 and 7), only esteem was significant (OR $=3.21,95 \% \mathrm{CI}$ : 1.6-6.6). The results of models 5, 6 and 7 are presented in Table 5 .

\section{DISCUSSION}

This cross-sectional analysis evaluated the effect of organisational work environment and personal factors on the prevalence of depressive symptoms among nurse manager population. Two work environment factors (effort-reward imbalance, specialty area) and two personal covariables (gender and sports activity) were found to be significantly associated with depressive symptoms in nurse managers, after adjustment for the other covariables. To the best of our knowledge, this is the first study to report the prevalence of depression symptoms of nurse managers and to 


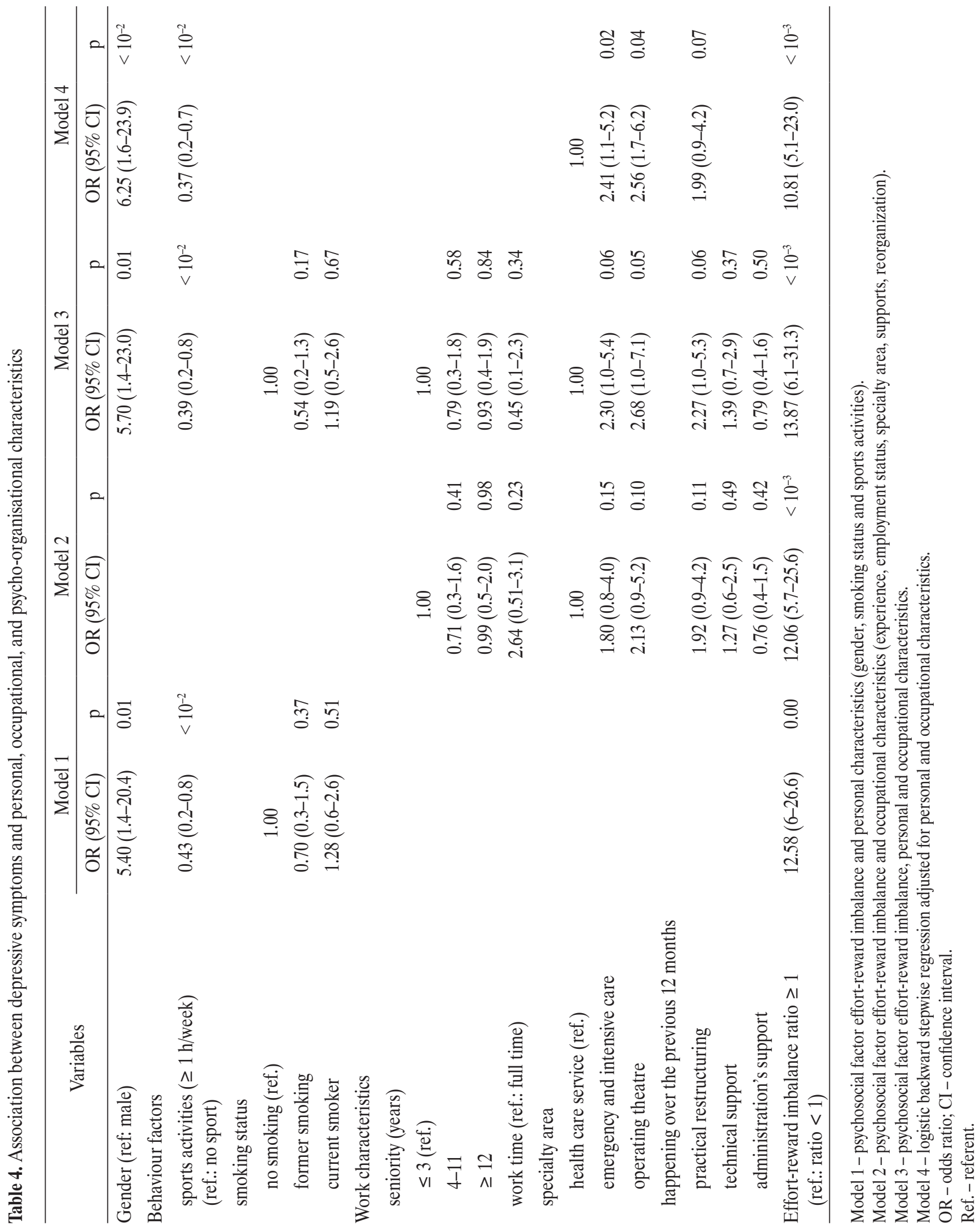



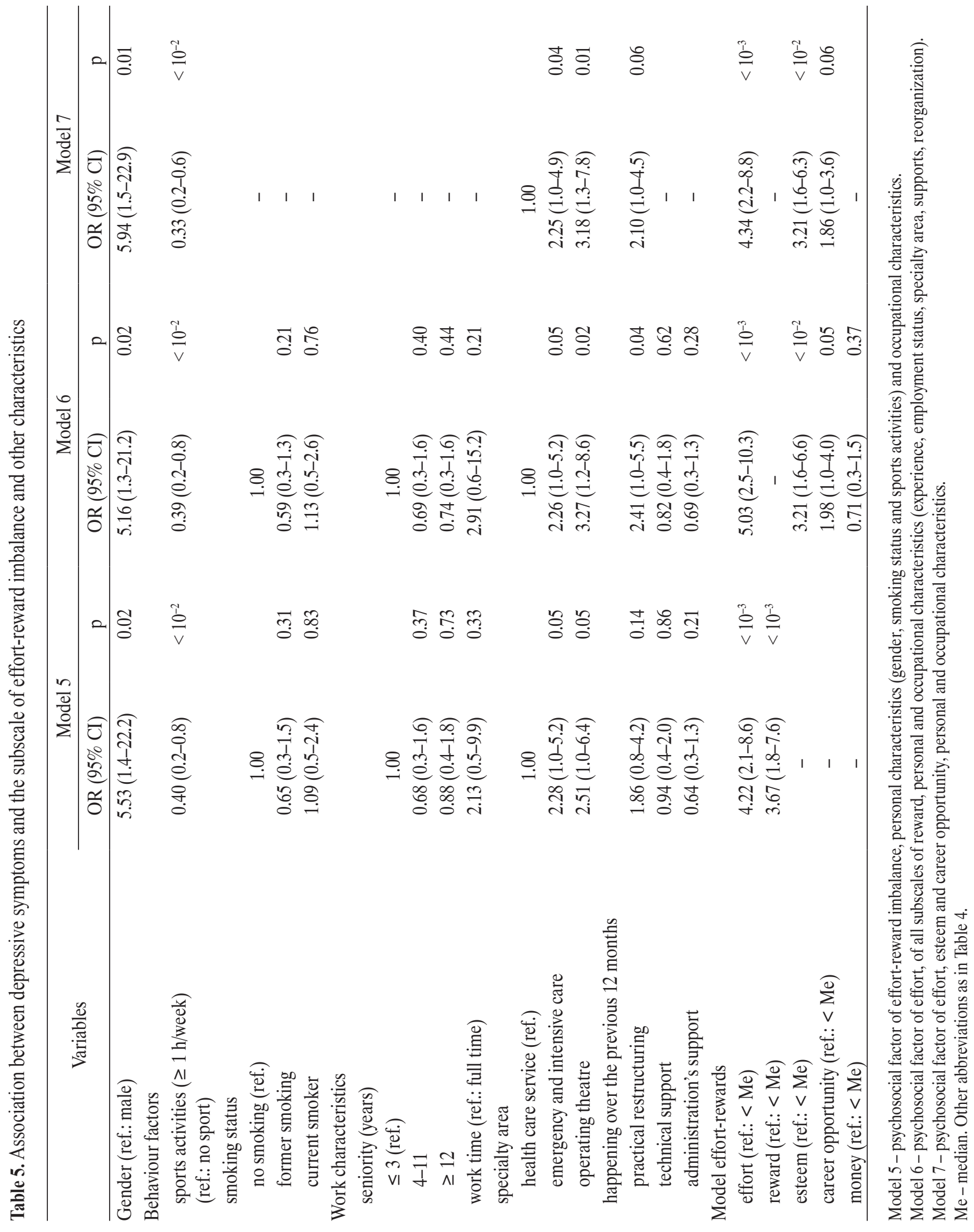
evaluate the strength of association between the effortreward imbalance and depressive symptoms for this population in France.

The prevalence of depressive symptoms in the previous 7 days was $30 \%$ in this study. The evaluation of depressive symptoms in this study was based on the CES-D scale (with a cut-point $\geq 17$ ), the mean score was 13.3. In France, a multi-site study was achieved between 1999 and 2003 to assess the prevalence of major psychiatric disorders using the Mini International Neuropsychiatric Interview [1]. They found a depressive occurrence in the previous 2 weeks representing a prevalence of about $11 \%$. The prevalence measured in other studies ranges from 5.8 over 12 months, to 11.9 over one month $[5,55,56]$. In a more recent study, Lamboy et al. (2005) measured a prevalence of $10 \%$ among females and $5.7 \%$ in males, and von Dem Knesebeck estimated the French depressive symptoms prevalence at about 9\% (CES-D with 8 items) [57]. Indeed, differences in depression prevalence between studies based on standardised diagnostic instruments (such as MINI) and on screening instruments (such as CES-D) can be significant.

Whatever method used, depressive symptoms among nurse managers are much higher $[1,4,5]$. It has to be noted that, in most population-based studies, the highest level of depression was found in the lower social classes [58].

In his study, Fanello also found a third of nurse managers with psychological distress assessed using GHQ-12 (mean score: 11.69; SD = 5.43). In the Press Next European study, $27 \%$ of nurse managers reported suffering of mental distress, $8.1 \%$ declaring to be followed by a physician $[31,32]$. Other studies showed that prevalence among registered nurses was lower than among nurse managers, whatever method used, but always higher than in the French general population [16,18,24].

The higher prevalence could be secondary of the choice of cut-point $(\geq 17)$. The analysis was also done with a different cut-point according to gender (female: $\geq 23$, male: $\geq 17)$. The population being mainly female, the prevalence was clearly lower (15.9\%) but still higher than the French general population prevalence [4,5,57].

Assessment of a stressful psychosocial work environment in this study was based on the effort-reward imbalance model. A total of $18 \%$ of nurse managers had an effort-reward imbalance with a mean effort-reward ratio of $0.78 \pm 0.4$ and a median reward score of 21 . Comparison with other results was difficult because the number of items used and the methods of calculating the effortreward ratio were different. The results of the main studies for which the comparison of figures is appropriate are summarized in Table 6.

No study of nurse managers has used the effort-reward model in France. Only one was found, it was carried out in Ontario, the effort-reward ratio was 0.69 (SD $=0.85), 10 \%$ of nurse managers had effort-reward ratio over one [30].

Jolivet et al. [16] also used the effort-reward imbalance model in the same way, on a sample of French health care workers population. For registered nurses and nursing aids, they found a mean effort score of $18.6(\mathrm{SD}=4.4)$ and 16.9 $(\mathrm{SD}=4.4)$, respectively, and a mean reward score of $18.5(\mathrm{SD}=4.9)$ and $18.3(\mathrm{SD}=4.4)$ [16]. Li et al. [27] described the results of the Press Next study, among the French sample of female registered nurses. They had a mean effort score of $15.4 \pm 4.2$ and a mean reward score of $18.8 \pm 6.3$ [27]. In Shanghai, Xie et al. studied a female nurse population with a mean effort-score of $18.9 \pm 5.4$ and a mean reward score of $21.1 \pm 8.11$ [59]. In other studies of health care workers, the effort-reward ratio (expressed in percentage or mean score) was higher or lower than our results, but the reward results of the other studies were still lower [14,60,61].

In France, the GAZEL study used the effort-reward model, $5.92 \%$ of males and $7.34 \%$ of females had an effortreward ratio over one. The studied population was a cohort that included 10174 subjects who were working at a French national electric and gas company (EDF-GDF) [42]. 


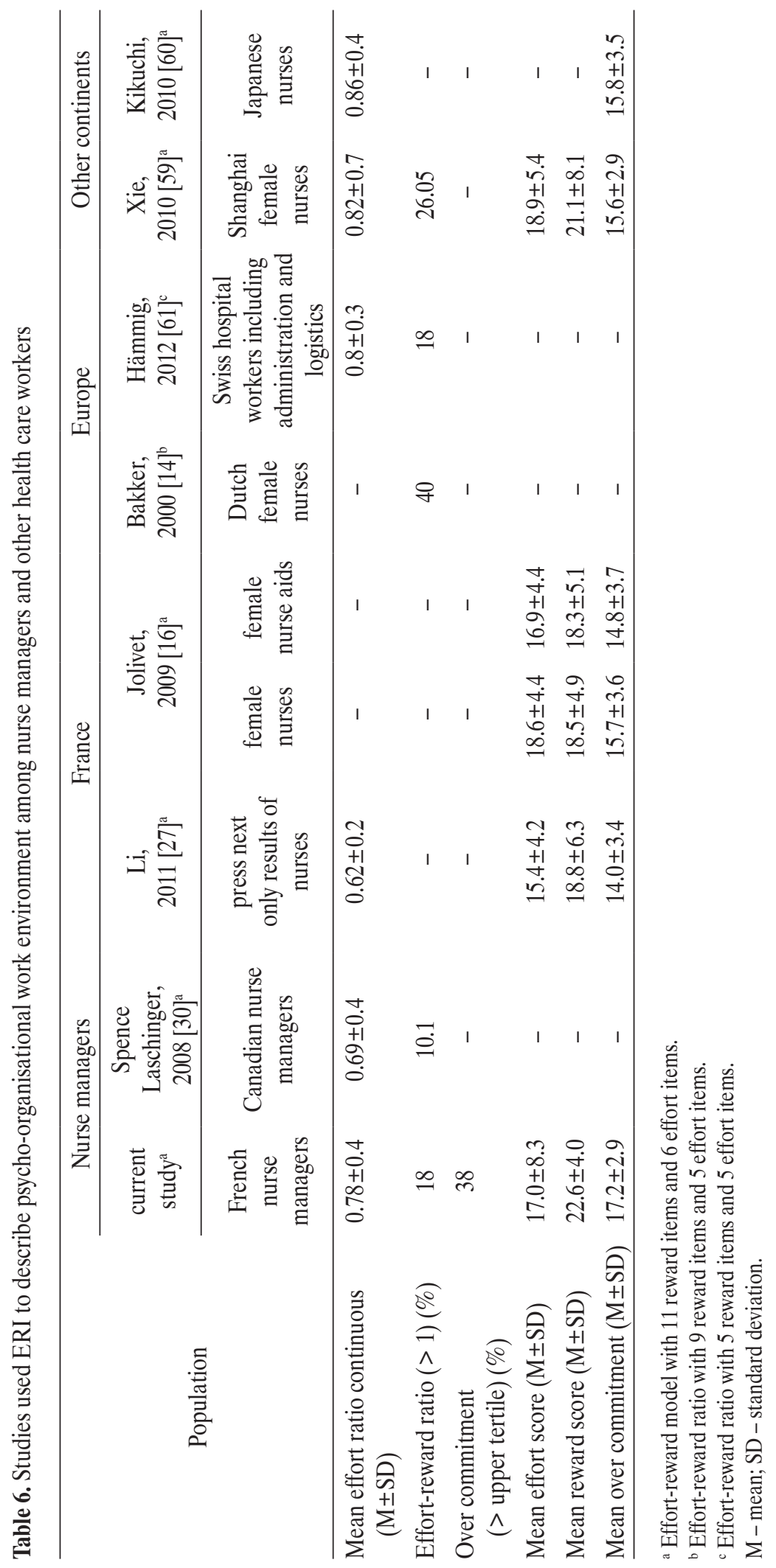


In a previous analysis of the GAZEL cohort, the mean reward score was significantly decreasing from ordinary workers to managers. However, they had no significant difference between occupational grades for mean effort score (for males) and over commitment (females and males) [43]. This is against our results because nurse managers had a higher reward and over commitment score than nurses or nurse aids $[16,27,59]$ and even physicians, according to one study [62]. Two hypotheses may explain these contradictory results. Indeed, there is a gap of 10 years between the 2 studies. Since in all of the sectors, work environment was modified, including the 35 -hour work week that has been in place in France since 1998, this resulted in the intensification of workload.

The second hypothesis is based on the particular situation of nurse managers in health care units. They are the only staff in the health care units that provide non or hardly any healthcare when it used to be their main responsibility. The role of nurse managers is the least visible activity in health care units; so they receive much less reward than the other workers in the staff.

Effort-reward ratio, effort, reward subscales in our study were each statistically significantly associated with depressive symptoms after adjustment for sociodemographic, behavioural and occupational factors. Our results confirmed those of several studies reporting significant associations between effort-reward imbalance and depressive symptoms $[33,38,45]$. The analysis with the ratio divided into tertiles showed a dose-dependent response as described in the literature $[12,17,30,59,62,63]$.

The association between depressive symptoms and effort reward imbalance is very strong in our study. This is also found in a few studies, especially among physicians. Thus, Hamming, in Switzerland, found an association between effort-reward imbalance and burnout with odds ratio ranging from 3.8 to 22.5 according to different professional categories of health care workers. The highest odds ratio was found for physicians [61]. Another Japanese study among hospital physicians showed an association between depressive symptoms and effort-reward imbalance, they also used the CES-D scale (cut-point $\geq 17$ ). The odds ratio ranged from $1.8(1.0-2.0)$ to $8.7(5.3-14.3)$ [62]. The situation of nurse managers may appear to be similar to that of physicians.

It can also be speculated that the high odds ratio was due to the choice of the cut-point of CES-D. The analysis was carried out a second time with a different cut-point for males and females. With the same variables as in model 3, the associations between depressive symptoms and gender, as well as specialty area, were no more significant. This can probably be explained by gender repartition in specialty areas. The gender distribution of specialty areas shows that there were a lot more males in emergency services $(15.7 \%)$ and operating theatres $(12.1 \%)$ than in health care units $(9.4 \%)$, but the difference was not significant.

The analysis with the subscales of reward shows that there is no association between gratification and depressive symptoms. Lindholm et al., in their study about Sweden nurse managers, found no significant association between psychosocial characteristics and salary either [28].

In the different models, a practical restructuring over the previous 12 months seems to be associated with depressive symptoms, while the architectural one was absolutely not associated.

This could be explained by higher and better resources, which might have been provided to carry out the architectural project.

Specialty area is also significantly associated with depressive symptoms. Specialty area was a dependent variable with a lot of other variables, including anxiety trait and gender. Other models (not shown) were made with anxiety trait and over commitment. The association between specialty area declined or was no more significant. Paterniti et al. in another analysis of GAZEL, showed that depressive symptoms (using CES-D) were significantly 
associated with psychosocial work environment irrespective of personality traits and covariates [64]. It is difficult to eliminate a reverse effect, but in terms of prevention, the nurse managers in emergency and intensive care units and operating theatres need special attention.

All in all, the nurse manager population presented more depressive symptoms than other occupational populations, and the results including the psychosocial organisational environment suggested an important issue. It is necessary to promote special interventions for them.

This study has several strengths. It is the first to assess depressive symptoms with a validated scale and the psycho-organisational work environment among such a large French population of nurse managers. Furthermore, their psycho-organisational work environment was not only based on the effort-reward model, but also questioned events that happened over the previous 12 months.

The sample contains only nurse managers, and not nurse manager chiefs. The proportion of males and females is similar to the one in the national population of nurse managers. Recruitment was carried out in various hospitals. Participation rate was satisfactory.

This study presents some limitations as well. First, recruitment was on a voluntary basis. Anonymous data collection did not allow to know the characteristics of the nonrespondents. Thus, the frequency of depressive symptoms could be overrepresented, since, nurse managers suffering from depressive symptoms might have been more likely to participate in the study. On the other hand, nurse managers with a major depression might have been on sick leave, and not participated. However, this limitation counter-balanced the participation rate of at least $60 \%$, which is a satisfactory participation rate.

The design of this study: cross-sectional design, is a limitation, and using self-perceived measures, too. A reverse causation cannot be excluded either. Depressive respondents may perceive their work environment less well. In our study, the univariate analysis showed there was a strong association between effort-reward ratio, over commitment and anxiety trait. We have opted to not include anxiety trait and over commitment in the models presented here. Their absence in the model does not change the odds ratio of the effort-reward ratio.

In spite of the cross-sectional design of this study, our findings clearly support the hypothesis of a high prevalence of depressive symptoms among nurse managers and a strong association with effort-reward imbalance. However, a more appropriate longitudinal study design is necessary to confirm the findings.

Past medical history of depression, stressful life events and stressful factors in home life were not available in this study. They are known risk factors of depression [65]. In this study, the primary purpose was to know the prevalence of depressive symptoms and of the effort-reward imbalance. To obtain the best rate of participation, it was opted not to include some questions about personal risk factors.

\section{CONCLUSION}

The study shows that nurse managers exposed to high effort-reward imbalance have a significantly increased odds ratio for depressive symptoms. Among reward, the lack of esteem is significantly associated with depressive symptoms and effort, too. The occurrence of practical restructuring appears to be associated with depressive symptoms. The study shows that nurse managers working in emergency and intensive care units, or operating theatres, have more depressive symptoms.

According to our findings, it seems necessary to continue research to explain the determinant factors of the effortreward imbalance and to find precisely which ones influence the health and mental health of nurse managers. A comparison with other health care workers, especially physicians and registered nurses, should be initiated to determine similarities and differences in order to adapt or develop appropriate preventive measures. 
These results allow to put forward possible measures for improvement of the psychological work environment of nurse managers. The first recommendation could be to improve reward, and especially esteem, which would be cheap. The second recommendation would be to pay more attention to nurse managers working in restructuring units, operating theatres and emergency and intensive care.

\section{REFERENCES}

1. Caria A, Roelandt J-L, Bellamy V, Vandeborre A. ["Mental Health in the General Population: images and realities (MHGP)": Methodology of the study]. Encephale. 2010;36 (3 Suppl):1-6, http://dx.doi.org/10.1016/S0013-7006(10) 70011-7. French.

2. Alonso J, Angermeyer MC, Bernert S, Bruffaerts R, Brugha TS, Bryson H, et al. Prevalence of mental disorders in Europe: Results from the European Study of the Epidemiology of Mental Disorders (ESEMeD) project. Acta Psychiatr Scand Suppl. 2004;(420):21-7, http://dx.doi.org/10.1111/ j.1600-0047.2004.00327.x.

3. Cohidon C, Santin G, Imbernon E, Goldberg M. Working conditions and depressive symptoms in the 2003 decennial health survey: The role of the occupational category. Soc Psychiatry Psychiatr Epidemiol. 2010;45(12):1135-47, http:// dx.doi.org/10.1007/s00127-009-0157-7.

4. Lamboy B, Léon C, Guilbert P. [Depressive disorders and use of health services in the French population according to the Health Barometer 2005]. Rev Epidemiol Sante Publique. 2007;55(3):222-7, http://dx.doi.org/10.1016/j.respe. 2006.11.005. French.

5. Lépine J-P, Gasquet I, Kovess V, Arbabzadeh-Bouchez S, Nègre-Pagès L, Nachbaur G, et al. [Prevalence and comorbidity of psychiatric disorders in the French general population]. Encephale. 2005;31(2):182-94, http://dx.doi.org/10.1016/ S0013-7006(05)82385-1. French.

6. Paris V, Renaud T, Sermet C. [Health account by pathology: prototype for 1998]. Paris: Centre de Recherche d'Étude et de Documentation en Économie de la Santé; 2003 Mai. Report No. 518. French.

7. Le Garrec M-A, Bouvet M, Koubi M. [National health account]. Série Statist. 2012;172:1-237. French.

8. Morvan Y, Prieto A, Briffault X, Blanchet A, Dardennes RM, Rouillon F, et al. [The depression in France: prevalence, associated factors and care consumption]. In: Beck F, Guilbert P, Gautier A, editors. [Health barometer 2005]. Paris: INPES; 2007. p. 459-85. French.

9. Hjarsbech PU, Andersen RV, Christensen KB, Aust B, Borg V, Rugulies R. Clinical and non-clinical depressive symptoms and risk of long-term sickness absence among female employees in the Danish eldercare sector. J Affect Disord. 2011;129(1-3):87-93, http://dx.doi.org/10.1016/j.jad. 2010.07.033.

10. Koopmans PC, Bültmann U, Roelen CAM, Hoedeman R, van der Klink JJL, Groothoff JW. Recurrence of sickness absence due to common mental disorders. Int Arch Occup Environ Health. 2011 Feb;84(2):193-201, http://dx.doi. org/10.1007/s00420-010-0540-4.

11. McIntyre RS, Liauw S, Taylor VH. Depression in the workforce: The intermediary effect of medical comorbidity. J Affect Disord. 2011 Jan;128 Suppl 1:S29-36, http://dx.doi. org/10.1016/S0165-0327(11)70006-4.

12. Stewart WF, Ricci JA, Chee E, Hahn SR, Morganstein D. Cost of lost productive work time among US workers with depression. JAMA. 2003;289(23):3135-44, http://dx.doi. org/10.1001/jama.289.23.3135.

13. Chang SM, Hong J-P, Cho MJ. Economic burden of depression in South Korea. Soc Psychiatry Psychiatr Epidemiol. 2012;47(5):683-9, http://dx.doi.org/10.1007/s00127011-0382-8

14. Bakker AB, Killmer CH, Siegrist J, Schaufeli WB. Effort-reward imbalance and burnout among nurses. J Adv Nurs. 2000;31(4):884-91, http://dx.doi.org/10.1046/j.13652648. 2000.01361.x.

15. Bonneterre V, Liaudy S, Chatellier G, Lang T, de Gaudemaris R. Reliability, validity, and health issues arising from 
questionnaires used to measure Psychosocial and Organizational Work Factors (POWFs) among hospital nurses: A critical review. J Nurs Meas. 2008;16(3):207-30, http:// dx.doi.org/10.1891/1061-3749.16.3.207.

16. Jolivet A, Caroly S, Ehlinger V, Kelly-Irving M, Delpierre C, Balducci $\mathrm{F}$, et al. Linking hospital workers' organisational work environment to depressive symptoms: A mediating effect of effort-reward imbalance? The ORSOSA study. Soc Sci Med. 2010;71(3):534-40, http://dx.doi.org/10.1016/j.socscimed.2010.04.003.

17. Van Vegchel N, de Jonge J, Meijer T, Hamers JPH, van Vegchel N, de Jonge J, et al. Different effort constructs and effort-reward imbalance: effects on employee well-being in ancillary health care workers. J Adv Nurs. 2001;34(1):128-36, http://dx.doi.org/10.1046/j.1365-2648.2001.3411726.x.

18. Estryn-Behar M, Le Nézet O, Duville N, Caillard JF. [Health and job satisfaction of health care workers in France and in Europe. Prevention of premature withdrawal from health care work]. 2005 [cited 2011 March 18]. Available from: http:// www.sante.gouv.fr/IMG/pdf/estrynbehar.pdf. French.

19. Schattner PL, Coman GJ. The stress of metropolitan general practice. Med J Aust. 1998 [cited 2012 Oct 28];169(3). Available from: https:/www.mja.com.au/journal/1998/169/3/ stress-metropolitan-general-practice.

20. Sutinen R, Kivimäki M, Elovainio M, Virtanen M. Organizational fairness and psychological distress in hospital physicians. Scand J Public Health. 2002;30(3):209-15, http:// dx.doi.org/10.1080/14034940210133843.

21. Visser MRM, Smets EMA, Oort FJ, de Haes HCJM. Stress, satisfaction and burnout among Dutch medical specialists. Can Med Assoc J. 2003;168(3):271-5.

22. Wilhelmsson S, Foldevi M, Akerlind I, Faresjö T. Unfavourable working conditions for female GPs. A comparison between Swedish general practitioners and district nurses. Scand J Prim Health Care. 2002;20(2):74-8, http://dx.doi. org/10.1080/02813430215560.

23. Williams ES, Konrad TR, Linzer M, McMurray J, Pathman DE, Gerrity M, et al. Physician, practice, and patient characteristics related to primary care physician physical and mental health: Results from the Physician Worklife Study. Health Serv Res. 2002;37(1):121-43.

24. Calnan M, Wainwright D, Almond S. Job strain, effort-reward imbalance and mental distress: A study of occupations in general medical practice. Work Stress. 2000;14(4): 297-311, http://dx.doi.org/10.1080/02678370110040920.

25. Lee H, Cummings GG. Factors influencing job satisfaction of front line nurse managers: A systematic review. J Nurs Manag. 2008;16(7):768-83, http://dx.doi.org/10.1111/j.13652834.2008.00879.x.

26. Duffield C, Roche M, O'Brien-Pallas L, Catling-Paull C, King M. Staff satisfaction and retention and the role of the nursing unit manager. Collegian. 2009;16(1):11-7, http:// dx.doi.org/10.1016/j.colegn.2008.12.004.

27. Li J, Galatsch M, Siegrist J, Müller BH, Hasselhorn HM. Reward frustration at work and intention to leave the nursing profession-prospective results from the European longitudinal NEXT study. Int J Nurs Stud. 2011;48(5):628-35, http://dx.doi.org/10.1016/j.jinurstu.2010.09.011.

28. Lindholm M, Dejin-Karlsson E, Ostergren P-O, Udén G. Nurse managers' professional networks, psychosocial resources and self-rated health. J Adv Nurs. 2003;42(5): 506-15, http://dx.doi.org/10.1046/j.1365-2648.2003.02650.x.

29. Suzuki E, Saito M, Tagaya A, Mihara R, Maruyama A, Azuma T, et al. Relationship between assertiveness and burnout among nurse managers. Jap J Nurs Sci. 2009;6(2):71-81, http://dx.doi.org/10.1111/j.1742-7924.2009.00124.x.

30. Spence Laschinger HK, Finegan J. Situational and dispositional predictors of nurse manager burnout: A time-lagged analysis. J Nurs Manag. 2008;16(5):601-7, http://dx.doi. org/10.1111/j.1365-2834.2008.00904.x.

31. Fanello S, Morlier-Tournelle C, Ripault B, Parot E, Kandouci B, David G, et al. [The psychological suffering of nurse managers: study on 97 managers from a teaching french hospital]. Arch Mal Prof. 2003;64(6):375-82. French.

32. Estryn-Behar M, Le Nézet O, Loriol M, Bedel M, Cantet Bailly N, Charton Promeyrat C, et al. [The situation of 
nurses' managers in France. European comparison]. Soins Form Pedagog Encadr. 2004;Suppl 52:1-61. French.

33. Netterstrøm B, Conrad N, Bech P, Fink P, Olsen O, Rugulies $\mathrm{R}$, et al. The relation between work-related psychosocial factors and the development of depression. Epidemiol Rev. 2008;30(1): 118-32, http://dx.doi.org/10.1093/epirev/mxn004.

34. Bonde JPE. Psychosocial factors at work and risk of depression: A systematic review of the epidemiological evidence. Occup Environ Med. 2008;65(7):438-45, http://dx.doi.org/ 10.1136/oem.2007.038430.

35. Stansfeld S, Candy B. Psychosocial work environment and mental health: A meta-analytic review. Scand J Work Environ Health. 2006;32(6):443-62, http://dx.doi.org/10.5271/ sjweh.1050.

36. Karasek RA. Job demands, job decision latitude, and mental strain: implications for job redesign. Adm Sci Q. 1979;24(2):285-308, http://dx.doi.org/10.2307/2392498.

37. Karasek RA, Brisson C, Kawakami N, Houtman I, Bongers P, Amick B. The Job Content Questionnaire (JCQ): An instrument for internationally comparative assessments of psychosocial job characteristics. J Occup Health Psychol. 1998;3(4): 322-55, http://dx.doi. org/10.1037/1076-8998.3.4.322.

38. Siegrist J. Adverse health effects of high-effort/low-reward conditions. J Occup Health Psychol. 1996;1(1):27-41, http:// dx.doi.org/10.1037/1076-8998.1.1.27.

39. Siegrist J, Starke D, Chandola T, Godin I, Marmot M, Niedhammer I, et al. The measurement of effort-reward imbalance at work: European comparisons. Soc Sci Med. 2004;58(8):1483-99, http://dx.doi.org/10.1016/S02779536(03)00351-4.

40. Niedhammer I, Siegrist J, Landre MF, Goldberg M, Leclerc A. [Psychometric properties of the French version of the Effort-Reward Imbalance model]. Rev Epidemiol Sante Publique. 2000;48(5):419-37. French.

41. Niedhammer I. Psychometric properties of the French version of the Karasek Job Content Questionnaire: A study of the scales of decision latitude, psychological demands, social support, and physical demands in the GAZEL cohort. Int Arch Occup Environ Health. 2002;75(3):129-44, http:// dx.doi.org/10.1007/s004200100270.

42. Niedhammer I, Tek M-L, Starke D, Siegrist J. Effort-reward imbalance model and self-reported health: Cross-sectional and prospective findings from the GAZEL cohort. Soc Sci Med. 2004;58(8):1531-41, http://dx.doi.org/10.1016/S02779536(03)00346-0.

43. Niedhammer I, Chastang JF, Gendrey L, David S, Degioanni S. [Psychometric properties of the French version of Karasek's "Job Content Questionnaire" and its scales measuring psychological pressures, decisional latitude and social support: The results of the SUMER]. Sante Publique. 2006;18(3):413-27, http://dx.doi.org/10.3917/spub.063. 0413. French.

44. Niedhammer I, Chastang J-F, Levy D, David S, Degioanni S, Theorell T. Study of the validity of a job-exposure matrix for psychosocial work factors: results from the national French SUMER survey. Int Arch Occup Environ Health. 2008;82(1):87-97, http://dx.doi.org/10.1007/s00420008-0311-7.

45. Godin I, Kittel F, Coppieters Y, Siegrist J. A prospective study of cumulative job stress in relation to mental health. BMC Public Health. 2005;5(1):67, http://dx.doi. org/10.1186/1471-2458-5-67.

46. Siegrist J. Chronic psychosocial stress at work and risk of depression: Evidence from prospective studies. Eur Arch Psychiatry Clin Neurosci. 2008;258 Suppl 5:115-9, http://dx.doi. org/10.1007/s00406-008-5024-0.

47. Sultan-Taïeb H, Lejeune C, Drummond A, Niedhammer I. Fractions of cardiovascular diseases, mental disorders, and musculoskeletal disorders attributable to job strain. Int Arch Occup Environ Health. 2011 Dec;84(8):911-25, http:// dx.doi.org/10.1007/s00420-011-0633-8.

48. Mäkinen A, Kivimäki M, Elovainio M, Virtanen M, Bond S. Organization of nursing care as a determinant of job satisfaction among hospital nurses. J Nurs Manag. 2003;11(5): 299-306, http://dx.doi.org/10.1046/j.1365-2834.2003.00399.x. 
49. Bégat I, Severinsson E. Reflection on how clinical nursing supervision enhances nurses' experiences of well-being related to their psychosocial work environment. J Nurs Manag. 2006;14(8):610-6, http://dx.doi.org/10.1111/j.13652934.2006.00718.x

50. Brinkert R. A literature review of conflict communication causes, costs, benefits and interventions in nursing. J Nurs Manag. 2010;18(2):145-56, http://dx.doi.org/10.1111/j.13652834.2010.01061.x.

51. Radloff LS. The CES-D Scale a Self-Report Depression Scale for Research in the General Population. Appl Psychol Measur. 1977;1(3):385-401, http://dx.doi. org/10.1177/014662167700100306.

52. Edwards MC, Cheavens JS, Heiy JE, Cukrowicz KC. A reexamination of the factor structure of the Center for Epidemiologic Studies Depression Scale: Is a one-factor model plausible? Psychol Assess. 2010;22(3):711-5, http://dx.doi. org/10.1037/a0019917.

53. Bonneterre V, Ehlinger V, Balducci F, Caroly S, Jolivet A, Sobaszek A, et al. Validation of an instrument for measuring psychosocial and organisational work constraints detrimental to health among hospital workers: The NWI-EO questionnaire. Int J Nurs Stud. 2011;48(5):557-67, http://dx.doi. org/10.1016/j.jinurstu.2010.09.006.

54. Elwood LS, Wolitzky-Taylor K, Olatunji BO. Measurement of anxious traits: a contemporary review and synthesis. Anxiety Stress Coping. 2012;25(6):647-66, http://dx.doi.org/ 10.1080/10615806.2011.582949.

55. Lépine JP, Gastpar M, Mendlewicz J, Tylee A. Depression in the community: the first pan-European study DEPRES (Depression Research in European Society). Int Clin Psychopharmacol. 1997;12(1):19-29, http://dx.doi.org/10.1097/ 00004850-199701000-00003.

56. Le Pape A, Lecomte T. [Prevalance and medical care of depression. In France in 1996-1997]. Paris: Centre de Recherche, d'Etudes et de Documentation en Economie de la Santé; 1999 Sep. Report No.: 485. French.
57. Von dem Knesebeck O, Pattyn E, Bracke P. Education and depressive symptoms in 22 European countries. Int J Public Health. 2010 Oct 21 [cited 2010 Nov 11]. Available from: http://www.ncbi.nlm.nih.gov/pubmed/20963468.

58. Fryers T, Melzer D, Jenkins R. Social inequalities and the common mental disorders: A systematic review of the evidence. Soc Psychiatry Psychiatr Epidemiol. 2003;38(5): 229-37, http://dx.doi.org/10.1007/s00127-003-0627-2.

59. Xie Z, Wang A, Chen B. Nurse burnout and its association with occupational stress in a cross-sectional study in Shanghai. J Adv Nurs. 2011;67(7):1537-46, http://dx.doi. org/10.1111/j.1365-2648.2010.05576.x.

60. Kikuchi Y, Nakaya M, Ikeda M, Narita K, Takeda M, Nishi M. Effort-reward imbalance and depressive state in nurses. Occup Med (Lond). 2010;60(3):231-3, http://dx.doi. org/10.1093/occmed/kqp167.

61. Hämmig O, Brauchli R, Bauer G. Effort-reward and worklife imbalance, general stress and burnout among employees of a large public hospital in Switzerland. Swiss Medical Weekly. 2012 May 31 [cited 2012 Nov 19]. Available from: http://www.smw.ch/content/smw-2012-13577.

62. Tomioka K, Morita N, Saeki K, Okamoto N, Kurumatani N. Working hours, occupational stress and depression among physicians. Occup Med (Lond). 2011;61(3):163-70, http:// dx.doi.org/10.1093/occmed/kqr004.

63. Griep RH, Rotenberg L, Landsbergis P, VasconcellosSilva PR. Combined use of job stress models and self-rated health in nursing. Rev Saúde Pública. 2011;45(1):145-52, http://dx.doi.org/10.1590/S0034-89102011000100017.

64. Paterniti S, Niedhammer I, Lang T, Consoli SM. Psychosocial factors at work, personality traits and depressive symptoms. Longitudinal results from the GAZEL Study. Br J Psychiatry. 2002 Aug;181:111-7.

65. Wang J, Schmitz N, Dewa C, Stansfeld S. Changes in perceived job strain and the risk of major depression: Results from a population-based longitudinal study. Am J Epidemiol. 2009;169(9):1085-91, http://dx.doi.org/10.1093/aje/kwp037.

This work is available in Open Access model and licensed under a Creative Commons Attribution-NonCommercial 3.0 Poland License - http://creativecommons.org/ licenses/by-nc/3.0/pl/deed.en. 